\section{0 grupo de relacionamentos afetivo-sexuais seguros para portadores de transtorno mental grave}

\section{The safe sexual-affective relationship group for individuals with severe mental disorders}

Caro Editor,

Portadores de transtorno mental grave (PTMG) são particularmente vulneráveis à epidemia do HIV/AIDS. A prevalência de infecção pelo HIV nestes sujeitos varia entre 3,1\% e 22,9\% nos Estados Unidos ${ }^{1}$. A Pesquisa em Soroprevalência de Aids na Saúde Mental (PESSOAS) investigou uma amostra de 2.238 adultos com transtorno mental em 26 instituições brasileiras. Durante os seis meses anteriores à pesquisa, 61,4\% eram sexualmente ativos, mas apenas $16 \%$ usaram preservativo ${ }^{2}$, enquanto $90 \%$ dos brasileiros são sexualmente ativos e $59 \%$ usam preservativos regularmente. No PESSOAS, a soroprevalência do HIV foi de $0,80 \%{ }^{2}$, mais alta que a da população geral $(0,65 \%)^{3}$. O Interdisciplinary Project on Sexuality, Mental Health, and AIDS (PRISSMA) com PTMG no Rio de Janeiro revelou que $42 \%$ praticaram sexo anal ou vaginal nos três meses anteriores ao levantamento, e apenas $22 \%$ dos sexualmente ativos usaram sempre preservativos ${ }^{3}$.

Disfunções sexuais também são altamente prevalentes em PTMG, afetando entre $30 \%$ e $80 \%$ das mulheres e $45 \%$ e $80 \%$ dos homens com esquizofrenia tratada ou não ${ }^{4}$, enquanto na população geral estas disfunções acometem 48,1\% das brasileiras e 50,9\% dos brasileiros. Poucos programas enfocam a prevenção de comportamentos sexuais de risco e a abordagem de disfunçôes sexuais em $\mathrm{PTMG}^{5}$, e mais escassos são os que utilizam avaliações pré e pós intervenção 5 . Objetivou-se avaliar, por meio de um grupo piloto, as problemáticas afetivo-sexuais mais prevalentes entre PTMG de um serviço para nortear intervençôes de pesquisa e terapêuticas.

O Hospital Dia Adulto (HDA) do Instituto de Psiquiatria do Hospital das Clínicas da Faculdade de Medicina da Universidade de São Paulo é um serviço de assistência 100\% voltada para a reabilitação psicossocial em grupos de PTMG. Trinta pacientes freqüentam o HDA de segunda a sexta-feira, das 8 às 16 horas. O Grupo de Relacionamentos Afetivo-Sexuais Seguros ingressou na grade de atividades do HDA em maio de 2009.

A análise do conteúdo de 27 sessões do grupo piloto embasou o desenho atual do programa, composto por avaliações pré e
Tabela 1: Temas das sessões do grupo piloto e classificação quanto ao tipo de abordagem

\begin{tabular}{|c|c|c|}
\hline & Temas & Intervenção \\
\hline 1 & $\begin{array}{l}\text { Relacionamento afetivo-sexual entre } \\
\text { pessoas com grande diferença de } \\
\text { idade }\end{array}$ & Terapêutica \\
\hline 2 & $\begin{array}{l}\text { O desinvestimento afetivo nas } \\
\text { relações a partir da doença mental }\end{array}$ & Terapêutica \\
\hline 3 & $\begin{array}{l}\text { A disfunção sexual em PTMG e as } \\
\text { repercussões na vida sexual do casal }\end{array}$ & Terapêutica \\
\hline 4 & $\begin{array}{l}\text { Sexo com profissionais pelo PTMG } \\
\text { como um meio de evitar a rejeição } \\
\text { por uma parceria afetiva }\end{array}$ & Terapêutica \\
\hline 5 & $\begin{array}{l}\text { Diferenças na resposta sexual e na } \\
\text { vivência da afetividade entre os } \\
\text { gêneros masculino e feminino }\end{array}$ & Psicoeducacional \\
\hline 6 & O sexo sob efeito de álcool e drogas & Psicoeducacional \\
\hline 7 & $\begin{array}{l}\text { A prática da masturbação por PTMG } \\
\text { sem parceria }\end{array}$ & Terapêutica \\
\hline 8 & $\begin{array}{l}\text { Quando usar preservativos } \\
\text { (relacionamento estável, casual, com } \\
\text { profissional)? }\end{array}$ & Psicoeducacional \\
\hline 9 & $\begin{array}{l}\text { Passividade ou atividade quanto à } \\
\text { iniciativa para o ato sexual pelo } \\
\text { homem e pela mulher. }\end{array}$ & Terapêutica \\
\hline 10 & $\begin{array}{l}\text { Repressão sexual dificulta que se } \\
\text { aborde a sexualidade mais } \\
\text { naturalmente }\end{array}$ & Terapêutica \\
\hline 11 & $\begin{array}{l}\text { PTMG como possível vítima de } \\
\text { assédio sexual }\end{array}$ & Psicoeducacional \\
\hline 12 & $\begin{array}{l}\text { Sexo oral e anal do ponto de vista } \\
\text { religioso e moral }\end{array}$ & Terapêutica \\
\hline 13 & $\begin{array}{l}\text { Quais motivos nos mantêm num } \\
\text { relacionamento onde não há atração } \\
\text { sexual }\end{array}$ & Terapêutica \\
\hline 14 & $\begin{array}{l}\text { As dificuldades do PTMG em } \\
\text { começar e terminar um } \\
\text { relacionamento }\end{array}$ & Terapêutica \\
\hline 15 & $\begin{array}{l}\text { Conhecimento superficial dos PTMG } \\
\text { do preservativo e contraceptivos }\end{array}$ & Psicoeducacional \\
\hline 16 & $\begin{array}{l}\text { Psicotrópicos e a amenorréia: mitos } \\
\text { associados à sexualidade feminina }\end{array}$ & Terapêutica \\
\hline 17 & $\begin{array}{l}\text { Riscos ao tentar conhecer alguém } \\
\text { para relacionamento por anúncio de } \\
\text { jornal ou por bate-papo na internet }\end{array}$ & Terapêutica \\
\hline 18 & $\begin{array}{l}\text { Como lidar quando o PTMG percebe } \\
\text { sentimentos amorosos por } \\
\text { profissionais da saúde que o tratam }\end{array}$ & Terapêutica \\
\hline 19 & $\begin{array}{l}\text { Efeitos dos psicotrópicos na resposta } \\
\text { sexual masculina }\end{array}$ & Terapêutica \\
\hline 20 & $\begin{array}{l}\text { Orientação homo, hetero e bissexual: } \\
\text { qual a nossa posição a respeito }\end{array}$ & Psicoeducacional \\
\hline 21 & $\begin{array}{l}\text { Como reagem os homens quando as } \\
\text { mulheres demonstram iniciativa para } \\
\text { o sexo }\end{array}$ & Terapêutica \\
\hline 22 & $\begin{array}{l}\text { Doenças sexualmente transmissiveis } \\
\text { e comportamento sexual de risco }\end{array}$ & Psicoeducacional \\
\hline 23 & Mulher PTMG e a gravidez & Terapêutica \\
\hline 24 & $\begin{array}{l}\text { PTMG e a maternidade ou a } \\
\text { paternidade }\end{array}$ & Terapêutica \\
\hline 25 & $\begin{array}{l}\text { PTMG e o primeiro encontro com } \\
\text { nova parceria }\end{array}$ & Terapêutica \\
\hline 26 & $\begin{array}{l}\text { Infidelidade nos relacionamentos } \\
\text { estáveis: qual a melhor atitude a } \\
\text { tomar? }\end{array}$ & Terapêutica \\
\hline 27 & $\begin{array}{l}\text { Transparência quanto aos } \\
\text { sentimentos amorosos ao longo do } \\
\text { relacionamento }\end{array}$ & Terapêutica \\
\hline
\end{tabular}


pós intervenção e por duas intervenções: psicoeducacional e terapêutica (Tabela 1).

O programa inicia-se por entrevistas individuais dos PTMG por psicóloga especialista em sexualidade (três encontros), quando preenchem: protocolo sobre relacionamentos afetivos (parceiros, amigos, família), sexuais (freqüência, práticas, disfunções), comportamento sexual de risco (sexo anal, oral, vaginal, com ou sem preservativos, número de parceiros estáveis e ocasionais), protocolo sobre conhecimento em sexualidade (anatomia, resposta sexual, ciclo menstrual, anticoncepção), saúde sexual (DST/AIDS) e sexo seguro (prevenção).

Posteriormente, os pacientes são submetidos à intervenção grupal psicoeducacional, desenvolvida em 7 sessóes semanais de 60 minutos, visando ampliar conhecimentos acerca da saúde sexual e sexo seguro (vide temas na Tabela 1). Após isso, respondem novamente ao protocolo sobre conhecimentos. $\mathrm{Na}$ sequência, os pacientes iniciam a intervenção grupal terapêutica, desenvolvida em 20 sessões semanais de 60 minutos, visando melhorar relacionamentos e disfunções sexuais (vide temas na Tabela 1). Finalmente, respondem novamente ao protocolo sobre relacionamentos e comportamento sexual de risco.

\section{Marco de Tubino Scanavino, Edna Teresinha Benatti} Hospital Dia Adulto do Instituto de Psiquiatria do

HCFMUSP

Programa de Estudos em Sexualidade (ProSex) do Instituto de Psiquiatria do HCFMUSP

Renato Del Sant Hospital Dia Adulto do Instituto de Psiquiatria do HCFMUSP

Financiamento e conflito de interesses

\begin{tabular}{|c|c|c|c|c|c|c|c|}
\hline $\begin{array}{l}\text { Membro do } \\
\text { grupo de } \\
\text { autores }\end{array}$ & $\begin{array}{l}\text { Local de } \\
\text { trabalho }\end{array}$ & $\begin{array}{l}\text { Verba de } \\
\text { pesquisa }\end{array}$ & $\begin{array}{c}\text { Outro } \\
\text { apoio à } \\
\text { pesquisa } \\
\text { ou } \\
\text { educação } \\
\text { médica } \\
\text { continuada }\end{array}$ & $\begin{array}{l}\text { Honorários de } \\
\text { palestrante }\end{array}$ & $\begin{array}{l}\text { Participação } \\
\text { acionária }\end{array}$ & $\begin{array}{c}\text { Consultor/Conselho } \\
\text { consultivo }\end{array}$ & Outro $^{3}$ \\
\hline $\begin{array}{c}\text { Scanavino } \\
\text { M de T }\end{array}$ & - & - & - & - & - & - & - \\
\hline Benatti ET & - & - & - & - & - & - & - \\
\hline Del Sant R & - & - & - & - & - & - & - \\
\hline
\end{tabular}

Referências

1. Pinto D de S, Mann CG, Wainberg M, Mattos P, Oliveira SB. Sexuality, vulnerability to HIV, and mental health: an ethnographic study of psychiatric institutions. Cad Saude Publica. 2007;23(9):2224-33.

2. Guimarães MD, Campos LN, Melo AP, Carmo RA, Machado CJ, Acurcio Fde A; PESSOAS Project Network Group. Prevalence of HIV, syphilis, hepatitis B and $\mathrm{C}$ among adults with mental illness: a multicenter study in Brazil. Rev Bras Psiquiatr. 2009;31(1):43-7.

3.Wainberg ML, McKinnon K, Elkington KS, Mattos PE, Gruber Mann C, De Souza Pinto D, Otto-Salaj L, Cournos F; Investigators of PRISSMA. HIV risk behaviors among outpatients with severe mental illness in Rio de Janeiro, Brazil. World Psychiatry. 2008;7(3):166-72.

4. Baggaley M. Sexual dysfunction in schizophrenia: focus on recent evidence . Hum Psychopharmacol. 2008;23(3):201-9.

5. Higgins A, Barker P, Begley CM. Sexual health education for people with mental health problems. What can we learn from literature? J Psychiatr Ment Health Nurs. 2006;13(6):687-97. 